\title{
Термоэлектрические преобразователи энергии: экологические аспекты
}

\author{
() Л.П. Булат, О.И. Сергиенко , В.А. Савоскула \\ Университет ИТМО, \\ 197101 Санкт-Петербург, Россия \\ ๑ E-mail: oisergienko@yandex.ru
}

(Получена 27 декабря 2016 г. Принята к печати 12 января 2017 г.)

Рассматриваются методологические основы оценки эколого-экономической эффективности термоэлектрических модулей для охлаждения на основе $\mathrm{Bi}_{2} \mathrm{Te}_{3}$ с учетом потребления ресурсов и экологических воздействий в жизненном цикле. Показано, что такой подход позволяет определить экологические аспекты термоэлектрического модуля и при необходимости найти пути для экологических улучшений, а также получить необходимую информацию для потенциальных инвесторов и других заинтересованных сторон.

DOI: 10.21883/FTP.2017.07.44656.42

Разработка экологически чистых твердотельных охладителей на основе создания новых термоэлектриков представляет актуальную научную задачу с точки зрения снижения экологического воздействия, поскольку, в отличие от используемых сегодня парокомпрессионных холодильных машин, стадия использования систем твердотельного охлаждения имеет практически нулевой потенциал глобального потепления.

Актуальность данной темы для мирового сообщества и России подтверждается принятием в декабре 2015 г. Парижского соглашения к „Рамочной конвенции об изменении климата“, в котором подчеркивается необходимость активизации действий по предотвращению изменения климата, в том числе, и путем развития и передачи социально и экологически оптимальных энергетических технологий [1]. В соответствии c „Энергетической доктриной РФ“ применение новых неуглеводородных источников энергии и технологий ее получения является актуальной задачей третьего этапа развития российского энергетического сектора, заключающейся в постепенном переходе к энергетике будущего с принципиально иными технологическими возможностями дальнейшего развития с опорой на высокоэффективное использование традиционных энергоресурсов [2].

Однако комплексная задача подбора экономически, экологически и технологически целесообразных материалов для высокоэффективных и конкурентоспособных твердотельных охладителей до сих пор не решена.

В связи с этим целью работы являлось исследование экологических аспектов систем твердотельного охлаждения в их жизненном цикле (ЖЦ) с применением методов экологического системного анализа: оценки жизненного цикла (ОЖЦ) и анализа ресурсной эффективности (АРЭ).

В качестве объекта исследования был выбран термоэлектрический модуль для охлаждения (ТЭМ) на основе $\mathrm{Bi}_{2} \mathrm{Te}_{3}$.
В работе рассматривается инвентаризационный анализ ЖЦ классической системы твердотельного охлаждения на основе $\mathrm{Bi}-\mathrm{Te}$ и определение экологических метрик, характеризующих материальную эффективность и потенциал глобального потепления (материальный и углеродный след) термоэлектрического охлаждающего модуля на примере электронного кулера для воды.

Метод оценки жизненного цикла продукции основан на сборе информации, сопоставлении и оценке входных и выходных потоков, а также возможных воздействий на окружающую среду на всем протяжении жизненного цикла продукционной системы путем количественного определения объемов потребленной энергии, материальных ресурсов и выбросов в окружающую среду; количественной и качественной оценки экологического воздействия; определения и оценки возможностей для улучшения экологического состояния системы (рис. 1) [3].

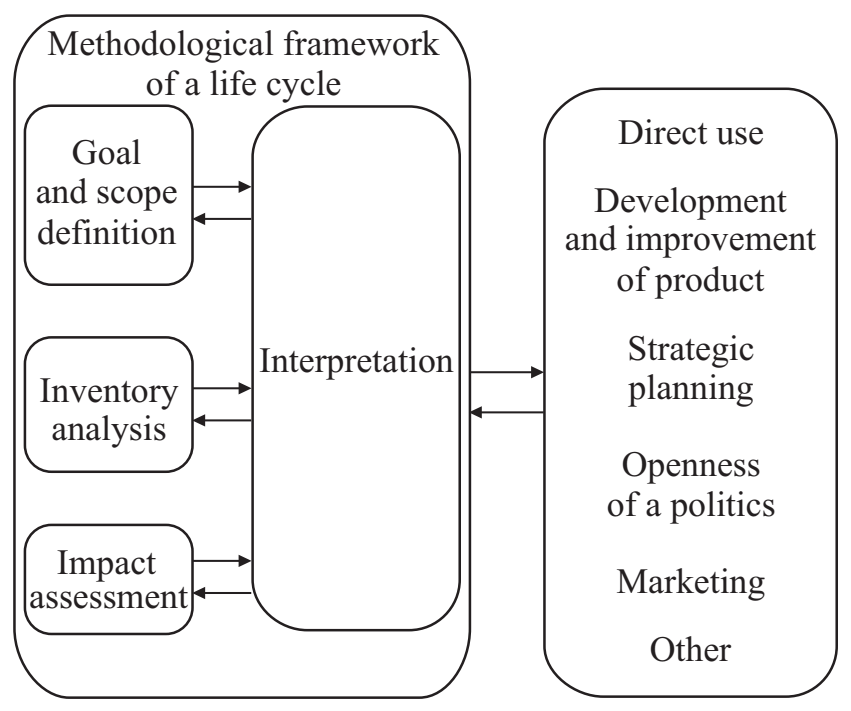

Рис. 1. Фазы жизненного цикла [3]. 


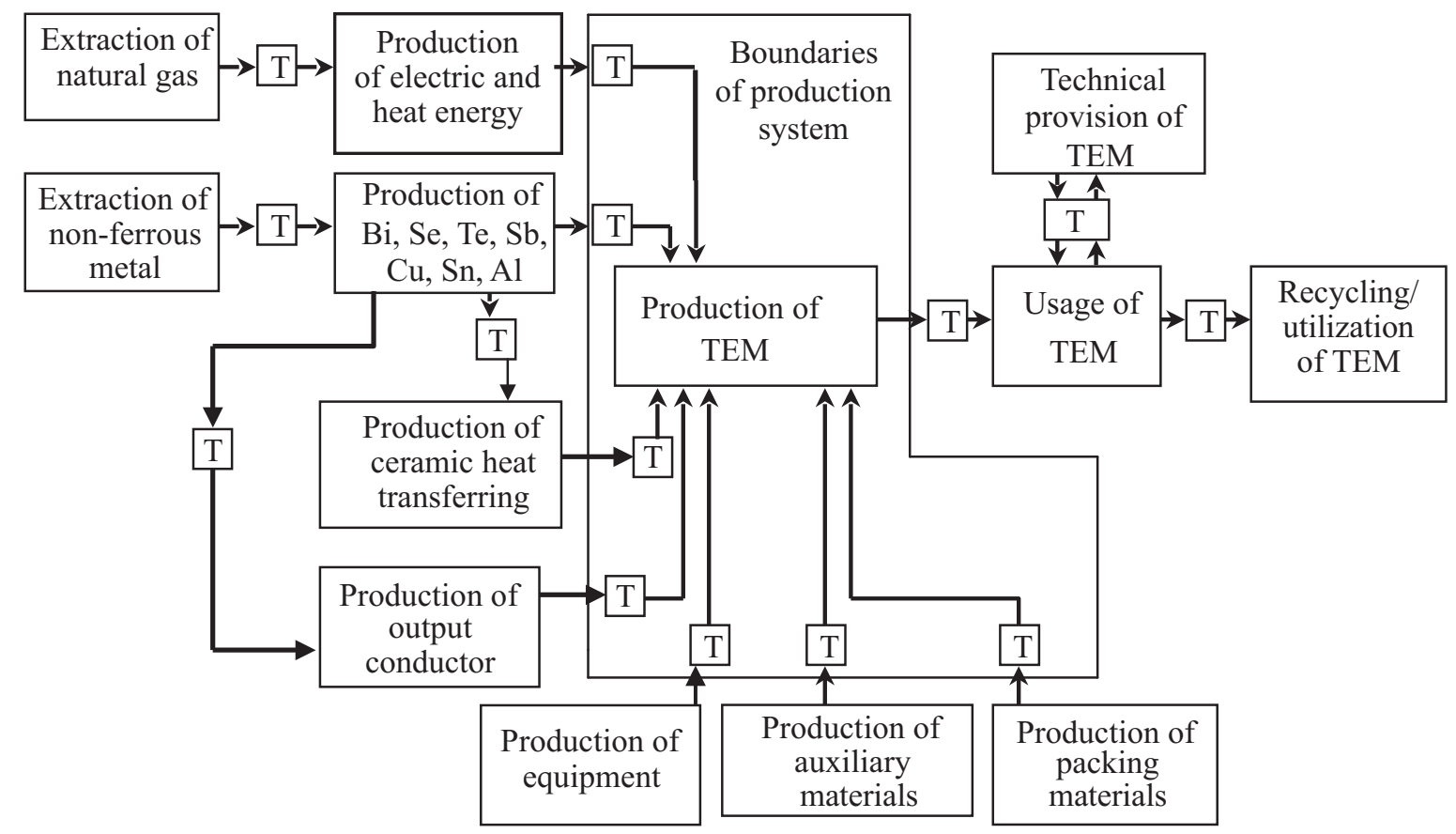

Рис. 2. Стадии жизненного цикла ТЭМ и границы продукционной системы.

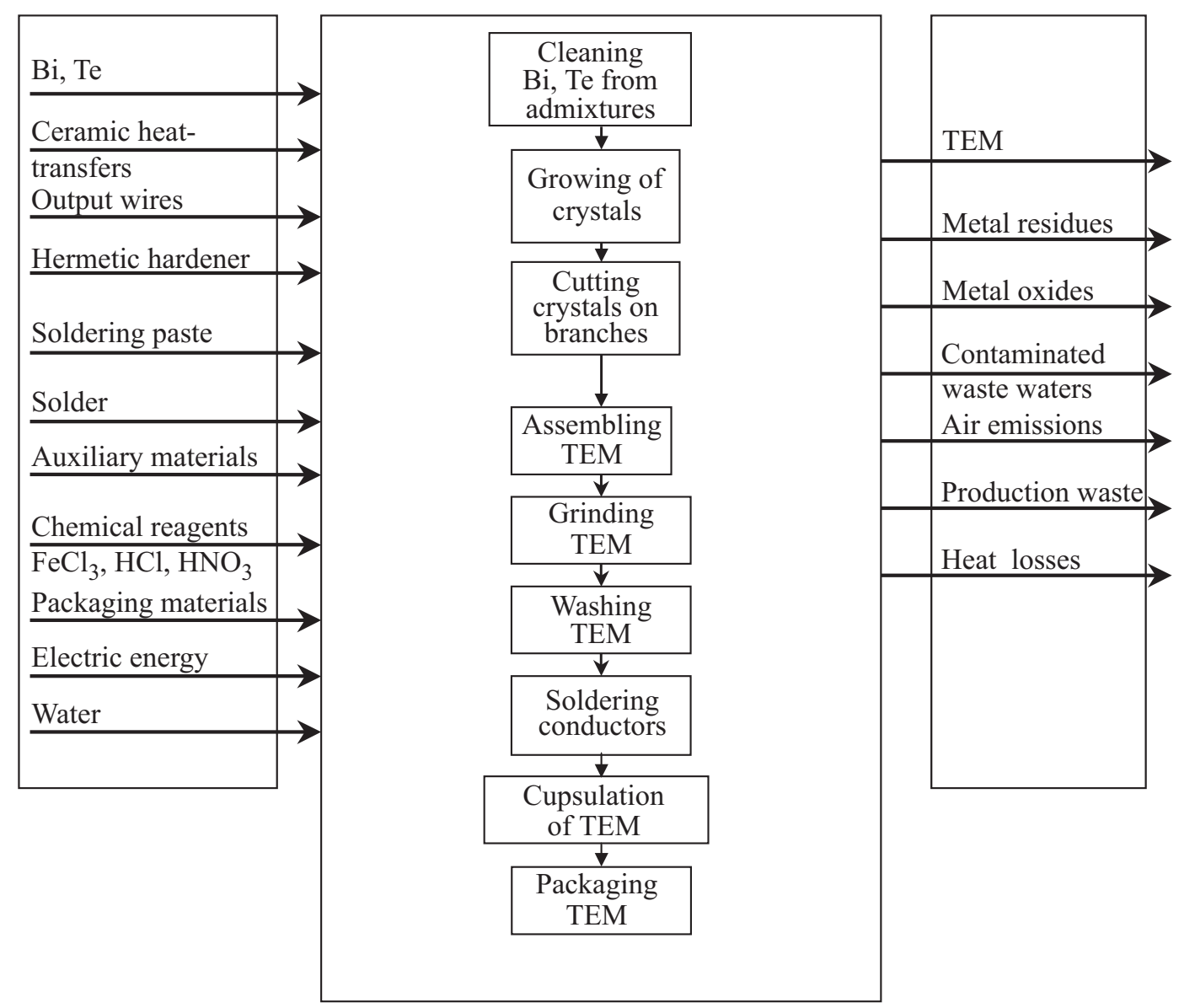

Рис. 3. Входные и выходные потоки на стадии производства ТЭМ. 
Категории воздействия „Истощение ресурсов“, индикаторы и параметры ОЖЦ

\begin{tabular}{|c|c|c|}
\hline Категория воздействия & Индикатор & Параметр \\
\hline $\begin{array}{l}\text { Истощение абиотических ресурсов } \\
\text { Истощение биотических ресурсов } \\
\text { Истощение водных ресурсов } \\
\text { Воздух } \\
\text { Эрозия почвы } \\
\text { Глобальное потепление } \\
\text { Образование фотохимического озона } \\
\text { Эвтрофикация } \\
\text { Закисление } \\
\text { Образование нетоксичных отходов }\end{array}$ & $\begin{array}{c}\text { MFab, кг/кДж } \\
\text { MFbi, кг/кДж } \\
\text { MFwa,кг/кДж } \\
\text { MFai, кг/кДж } \\
\text { MFer, кг/кДж } \\
\text { ПГП } \\
\text { ПОФО } \\
\text { ПЭФ } \\
\text { ПЗ } \\
\text { ПОО }\end{array}$ & 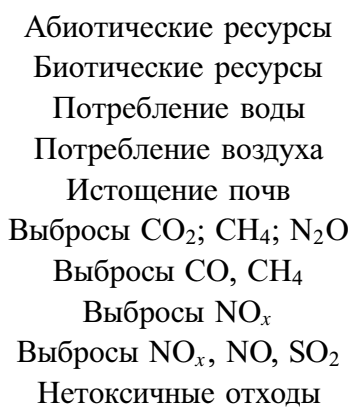 \\
\hline
\end{tabular}

Основными категориями воздействий на окружающую среду являются использование ресурсов, здоровье человека и глобальные экологические воздействия. Определение цели, области применения, а также выполнение инвентаризационного анализа проводились в соответствии с требованиями международного стандарта ИСО 14041 (рис. 1) [3].

Применительно к объекту исследования стадии жизненного цикла включают производство термоэлектрических материалов; сборку термоэлектрического модуля, производство изделий, в составе которых будут использоваться термоэлектрические материалы; использование изделий, включая техническое обслуживание; переработку или утилизацию отходов после окончания срока жизни (рис. 2). Стадия эксплуатации ТЭМ должна рассматриваться в составе изделия, например электронного кулера для воды. Для сравнительного анализа твердотельного охлаждения с традиционным, парокомпрессионным был рассмотрен компрессионный кулер для воды.

Структура единичных процессов изготовления ТЭМ показана на рис. 3.

Метод анализа ресурсной эффективности (АРЭ) в отличие от ОЖЦ основан на рассмотрении только входных материальных и энергетических потоков ресурсов в цепочке создания продукции. Определение ресурсной эффективности в жизненном цикле выполняется на основе методики MIPS-анализа [4]. Показатель MIPS (от англ. Material Input per Product or Service Unit) представляет собой удельную ресурсоемкость, характеризующую материальный вход на единицу продукции или услуги [5].

Категории экологического воздействия при выполнении ОЖЦ и АРЭ включают потребление всех видов материальных ресурсов MF, пересекающих границы продукционной системы и глобальные категории (см. таблицу) [6].

Расчет MIPS может быть выполнен с использованием предварительно вычисленных МІТ-коэффициентов, представляющих среднюю ресурсоемкость материала, что позволяет избегать сложных и трудоемких расчетов получения первичных ресурсов. Наиболее полная база МІТ-коэффициентов для различных материалов публикуется и постоянно обновляется Вуппертальским Институтом климата (Wuppertal, Germany) [7]. Для анализа ресурсной эффективности термоэлектрических материалов требуется расширение существующих баз данных.

На рис. 4-6 показана структура потоков абиотических ресурсов и потребление воды на стадии производства ТЭМ в целом и в единичных процессах по данным выполненного АРЭ. Основной вклад в структуру материального потребления вносят керамический теплопереход - 67\%, паяльная паста - $12 \%$, провода $14 \%$, вклад других материалов суммарно составляет 7\% (висмут, теллур, герметик, отвердитель, моющее средство, ацетон, припой, клей, абразив, декапирующий раствор, промывочная жидкость и упаковочные материалы)

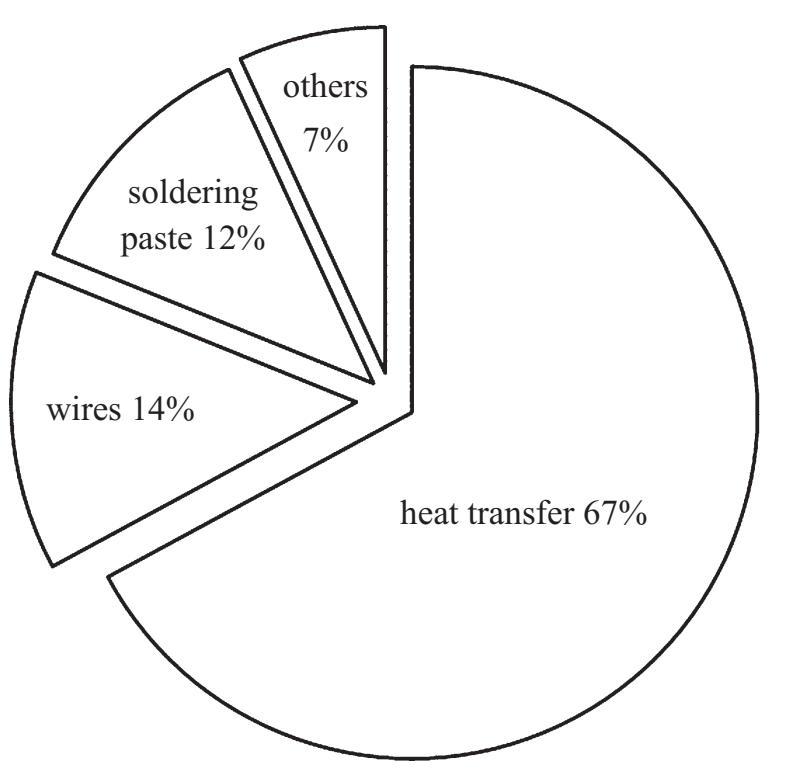

Рис. 4. Структура потока абиотических ресурсов на стадии производства ТЭМ. 


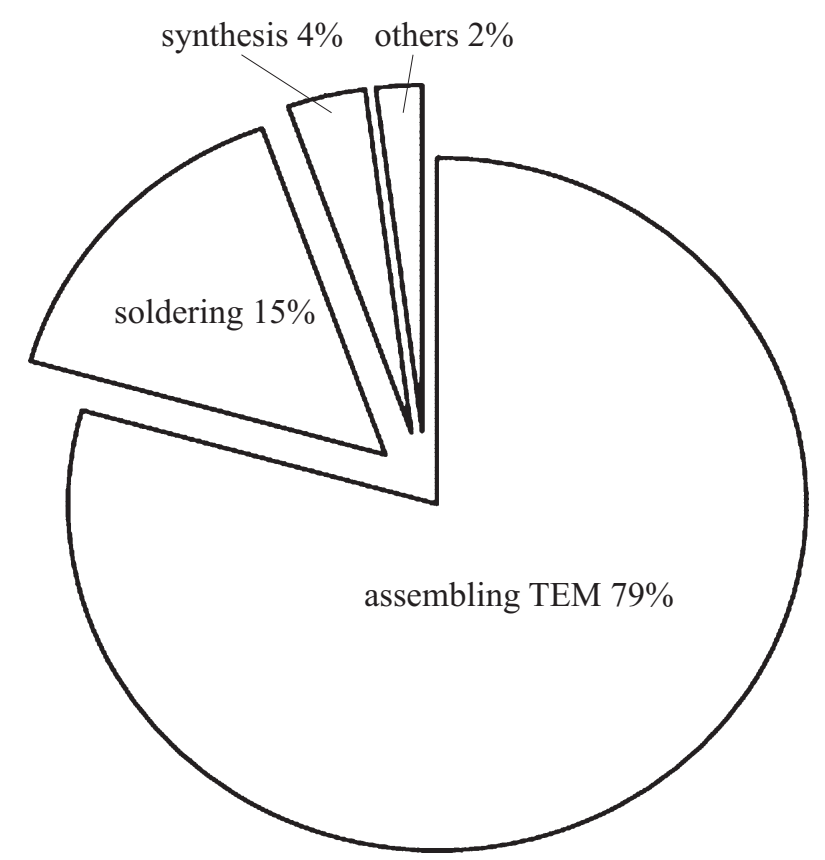

Рис. 5. Распределение потока абиотических ресурсов по единичным процессам на стадии производства ТЭМ.

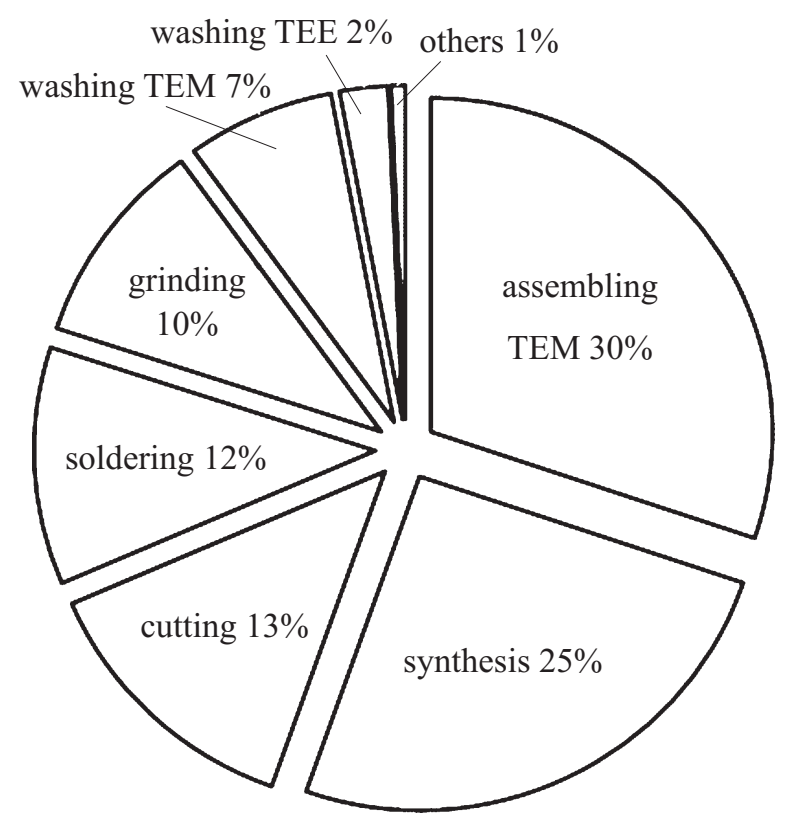

Рис. 6. Потребление воды в единичных процессах на стадии производства ТЭМ.

(рис. 4). Из единичных процессов производства ТЭМ наиболее ресурсоемким является сборка ТЭМ - 79\% и пайка $-15 \%$, среди других единичных процессов, вклад которых составляет $2 \%$, - резка, мойка, шлифовка, герметизация и упаковка (рис. 5). Наиболее водоемкими являются процессы сборки - 30\% и синтеза - 25\%, среди других процессов с вкладом менее $1 \%$ - герметизация и упаковка ТЭМ (рис. 6).
C помощью программного продукта LCA Light Tools, разработанного Шведским институтом экологических исследований, на основании данных о выделении парниковых газов в единичных процессах производства ТЭМ был рассчитан потенциал глобального потепления (ПГП) и потенциал фотохимического образования озона (ПФОО) [4]. За период воздействия продолжительностью 100 лет расчетное значение ПГП составляет 3015 г CO $_{2}$-эквивалента/г, и ПФОО составляет 86.2 г этан-эквивалента. Основной вклад в ПГП и ПФОО вносит энергия, потребляемая в процессе производства.

Выполнение ОЖЦ и АРЭ связано с неопределенностями, вызванными отсутствием точных данных о материальном потреблении при производстве некоторых материалов. Для повышения надежности полученных результатов был выполнен анализ чувствительности результатов ОЖЦ при варьировании исходных данных. Анализ чувствительности показал, что в целом показатели ПГП, ПФОО и MIPS не чувствительны к неопределенностям в исходных данных.

Дальнейшее исследование экологических аспектов термоэлектрических преобразователей энергии определяется потребностью и актуальностью вызовов и проблем развития нетрадиционных источников энергии и повышения их ресурсной эффективности; выявление экологических аспектов приборов и устройств твердотельного охлаждения в жизненном цикле позволит подтвердить их экологическую безопасность на стадиях производства, эксплуатации и утилизации. Методические рекомендации по выполнению ОЖЦ и АРЭ могут быть использованы для целей экодизайна термоэлектрических охладителей.

\section{Список литературы}

[1] Рамочная конвенция об изменении климата. Принятие Парижского соглашения.

http://unfecc.int/resource/docs/2015/cop21/rus/109r01r.pdf (Дата обращения 31.12.2015).

[2] Энергетическая стратегия РФ на период до 2030 г. Утв. Распоряжением правительства РФ от 13 ноября 2009 г., № 1715 -p.

[3] ГОСТ Р ИСО 14040-99. Управление окружающей средой. Оценка жизненного цикла. Принципы и структура.

[4] Основы теории экоэффективности. Монография, под науч. ред. О. Сергиенко, Х. Рона (СПб., СПБГУНиПТ, 2004).

[5] C. Liedtke, K. Bienge, K. Wiesen, J. Teubler, K. Greiff, M. Lettenmeier, H. Rohn. Resource, 3, 544 (2014).

[6] О.И. Сергиенко, Л.П. Булат, С.Е. Копыльцова, В.А. Староверова, М.Е. Гужва, А.С. Виноградов. Термоэлектричество, 4, 5 (2010).

[7] Material Intensity of Materials, Fuels, Transport Services, Foods (MIT). Wuppertal Institute http://wupperinst.org/uploads/tx_wupperinst/MIT_2014.pdf (Дата обращения 31.12.2015).

Редактор А.Н. Смирнов 


\section{Thermoelectric energy converters: environmental aspects}

\section{Bulat, O. Sergienko, V. Savoskula}

ITMO University,

197101 St. Petersburg, Russia

Abstract The article discusses methodological framework for the assessment of environmental and economic efficiency of thermoelectric modules for cooling based on $\mathrm{Bi}_{2} \mathrm{Te}_{3}$ considering resource consumption and environmental impact in the life cycle. It is shown that this approach allows identifying the environmental aspects of thermoelectric module, and, if appropriate, finding ways for environmental improvements, as well as the necessary information to potential investors and other stakeholders.

Публикация материалов Конференщии завершена. 